Estudios Románicos, Volumen 28, 2019, pp. 417-421

ISSN: 0210-491

eISSN: 1989-614X

DOI: https://doi.org/10.6018/ER/348371

\title{
LA RECEPCIÓN DE CERVANTES EN LOS SIGLOS XX Y XXI: ITINERARIOS DEL MITO DEL QUIJOTE EN DISTINTAS ARTES
}

Editora: Paloma Ortiz de Urbina

Cervantes en los siglos XX y XXI. La recepción actual del mito del "Quijote». Peter Lang AG, 2018 (Internationaler Verlag der Wissenschaften), 368 p.

(ISBN: 3034332084)

\section{Carmen María López López* \\ Universidad de Murcia}

La condición de aquello que, en términos literarios o artísticos llamamos clásico, se mide en virtud de su inagotabilidad y legado perpetuo, moldeable a distintas formas, estilos y modos de decir una misma semilla originaria. Cervantes y su criatura literaria -el Quijote- se avienen a esta estirpe de creaciones inagotables, tal como revela el volumen titulado Cervantes en los siglos XX y XXI. La recepción actual del mito del Quijote, editado por Paloma Ortiz de Urbina Sobrino y publicado por la prestigiosa editorial Peter Lang en la colección "Perspectivas hispánicas". La obra que nos ocupa tiene la virtud de cristalizar miradas muy diversas en torno a la figura del Quijote, analizando su relieve en áreas de conocimiento tan plurales como la literatura, la historia, la filosofía, la música o los medios audiovisuales como el cine o las series de televisión. Resultado del congreso internacional "La recepción de Cervantes en los siglos XX y XXI. Mitos y leyendas" celebrado los días 5, 6 y 7 de octubre de 2016 en el Rectorado de la Universidad de Alcalá de Henares, bajo la coordinación de Paloma Ortiz de Urbina, directora del grupo RECEPTION, Estudios de Recepción, es esta selección tan exquisita que compendia los estudios de mayor calidad literaria presentados a dicho simposio.

A nivel estructural la obra se divide en seis grandes bloques de contenido en virtud de las áreas temáticas que ocupan el centro de interés de los investigadores: la recepción de Cervantes en la actualidad, Cervantes en la literatura, Cervantes en la música, Cervantes en los medios audiovisuales, Cervantes en la filosofía y en la historia, y Cervantes en otras lenguas y culturas.

* Dirección para correspondencia:cmlopez@ucam.edu 
Será el cervantista francés Jean Canavaggio quien inaugure el capítulo primero al ofrecer un trabajo de recepción eminentemente pluriforme y multidisciplinar del personaje cervantino. Su estudio "Algunas aventuras de Don Quijote en Francia en el siglo XX" marca las áreas de incidencia de la figura del Quijote en el país galo. Canavaggio se centra para ello en parcelas muy dispares de su recepción, como las traducciones al francés, la presencia del Quijote en piezas musicales como el Don Quichotte (1910) de Jules Massenet, Tres canciones españolas (1934) de Maurice Ravel y la versión francesa L'Homme de la Mancha (1968) de Jacques Brel a partir del musical estadounidense The Man of La Mancha (1964), con texto de Joe Darion y música de Mitch Leigh. Lecturas tan plurales como las psicoanalíticas de René Girard o Marthe Robert, así como los trabajos de los hispanistas franceses Pierre Villar y Michel Foucault ocupan un espacio de su reflexión. Por último, Canavaggio explora las propuestas iconográficas del personaje cervantino que, desde la semilla esparcida en los grabados de Gustave Doré, se proyectan en los trabajos de Gérard Garouste, ilustrados del Quijote (1998) de Diane de Selliers. En definitiva, desde la exégesis de las traducciones, pasando por el despliegue de piezas musicales, hasta llegar al legado de lecturas psicoanalíticas o a la reflexión sobre los elementos iconográficos de estirpe cervantina, el estudio de Canavaggio se revela pluralmente valioso para abordar esta figura literaria en el país galo.

El segundo capítulo se centra en la recepción del Quijote en distintas literaturas de proyección europea y mundial. En el marco de la narrativa norteamericana, Esther Bautista Naranjo traza en "Cervantes and Bradbury: Bibliocausts and Libresque Utopias in Times of Crisis" una analogía entre el Quijote de Cervantes y Fahrenheit 451 (1953) del novelista norteamericano Ray Bradbury. Los lazos que vinculan ambas producciones se advierten a partir de la quema de libros como modo de denunciar los peligros de la censura y las amarras de la tiranía. Ante el ambiente opresivo, el amor por los libros se erige como salvaguarda de la integridad moral del ser humano. Enriquecen la recepción de Cervantes en la literatura escrita en lengua alemana los estudios de Lorena Silos ("Una lanza por la libertad: el Quijote de Max Frisch", sobre el teatro suizo, género del Hörspiel o radionovela (Max Frisch); Tilman Klinge ("Erich Kästner: Don Quichotte - eine Nacherzählung für Kinder?") en la literatura infantil alemana de Erich Kästner, y Carmen Alonso Ímaz ("Cervantes, de Bruno Frank: algunos mitos de su visión en la España de Felipe II") en la novela histórica de Bruno Frank. Volviendo a la tradición hispánica, Pilar Úcar Ventura ("El Caballero del Verde Gabán y cómo leer el Quijote en el siglo XXI") se aproximará a algunos horizontes de lectura de este episodio cervantino, tal como han sido interpretados por parte de la crítica. Concluyen la sección dedicada a Cervantes en el formato del cómic o la narrativa gráfica alemana los asedios de Matías Martínez (“Don Quijote als Literaturcomic - Reduktion oder Transformation narrativer Komplexität?") e Ingrid Cáceres Würsig ("Cervantes en el siglo XXI: análisis intertextual del 'Quijote' en un cómic alemán”). El estudio de Matías Martínez adopta un método comparado para reflexionar sobre tres cómics inspirados en el Quijote: The Last Knight (2000) de Will Eisner, The Complete Don Quixote (2011) de Rob Davis y Don Quijote (2012) de Flix. Por su parte, Ingrid Cáceres se centrará en el cómic de Flix para abordar las transposiciones técnicas de la obra cervantina (metaficción y autorreferencialidad) en el formato de la narrativa gráfica. 


\section{LA RECEPCIÓN DE CERVANTES EN LOS SIGLOS XX Y XXI: ITINERARIOS DEL MITO DEL QUIJOTE EN DISTINTAS ARTES - Editora: Paloma Ortiz de Urbina}

La presencia de Cervantes en el horizonte musical de los siglos XX y XXI es notoria en el capítulo tercero de la monografía. En concreto, el estudio de Hans Christian Hagedorn aporta una revisión minuciosa acerca de la presencia del escudero de don Quijote en el género jazzístico. El legado de Sancho Panza en el jazz cristaliza en innumerables ejemplos musicales, entre los que se cuentan el tema instrumental Barataria (1925) de Albert Brunies and His Half Way House Orchestra; Sancho Panza, un tema instrumental compuesto por Johnny Richards (1911-1968) e interpretado por el saxofonista Sonny Stitt (1924-1982); Sancho, obra del trombonista Leopoldo "Pucho" Escalante, grabada en 1964 por el compositor y su Grupo Cubano de Jazz e incluida en el álbum Jazz Cuba (1964). La primera suite de jazz dedicada al Quijote fue Windmill Tilter: The Story of Don Quixote, del trompetista y compositor canadiense Kenny Wheeler (1930-2014). Ya en el jazz del siglo XXI destaca, entre otras, el tema instrumental Sanchopanza, del grupo italiano Actis Band, compuesta por el saxofonista Carlo Actis Dato e incluida en el álbum Don Quijote, integrando distintos estilos como el jazz de vanguardia, free jazz, jazz experimental, jazz rock con elementos del folk mediterráneo.

El siguiente estudio de Trevor Walshaw ("Roberto Gerhard: The Knight of the Hidden Images") profundiza en la huella del Quijote en el compositor Roberto Gerhard. $\mathrm{Al}$ profundizar en los aspectos técnicos de esta música para ballet, se aprecia cómo el compositor ha revelado la esencia del personaje cervantino y, concretamente, su búsqueda de una realidad idealizada. Continuando con la obra del compositor Roberto Gerhards, será Gabriela Lendle quien aborde su particular Don Quixote ("Die musikalische Rezeption des Pastoral-Topos und der Mythos des spanischen pueblo in Roberto Gerhards Don Quixote"). Se centra para ello en el tópico de la vida bucólica y su cristalización en el lenguaje de la música. Cierra este bloque temático dedicado a la música el estudio de Jesús Ferrer Cayón ("Un ingenioso hidalgo en América (2005): la recepción del mito cervantino en la cantata escénica de Samuel Máynez y Luis Bacalov"). El legado del Quijote en la citada cantata escénica, compuesta por el maestro italo-argentino Luis Bacalov sobre el texto del violinista y escritor mexicano Samuel Máynez, y estrenada el 27 de mayo de 2005 en el Teatro Juárez de Guanajuato, revela una visión del personaje como símbolo del hermanamiento cultural por la vía de la reinterpretación del mito en clave latinoamericana. A partir de este contexto de recepción pueden dilucidarse ideas nucleares: el exilio republicano espñaol, la ensoñación y deslocalización americanas de Cervantes, el realismo mágico, la utopía, la mirada vuelta al pasado precolombino, la crítica al imperialismo de la monarquía e iglesia católicas, así como la libertad heroica quijotesca del naciente humanismo moderno.

Continuando la ordenación temática que vertebra los contenidos del volumen, cuatro son los estudios confinados a la proyección del mito cervantino en los medios audiovisuales. Inicia el recorrido el estudio de Carlos Alvar: "Tradición e innovación: el Quijote en el cine". El acopio de adaptaciones cinematográficas dedicadas al personaje cervantino deja sentir la influencia de la iconografía de Gustave Doré en la composición del cuadro de la imagen cinematográfica, pasando por el análisis de temas centrales como los molinos de viento, la muerte de don Quijote, Dulcinea, teatro y marionetas, y procesos judiciales. El corpus integrado por veinte películas de directores 
tan memorables como Nonguet-Zecca, Morlhon, Pabst, Iwerks, Gil, Kózintsev, Kristl, Grimaldi, Gavaldón, Hiller, Garnier, Scaparro, Welles, Yates, Fulton, Serra, Alcázar, Pozo o Zurera, da idea de la riqueza de este friso en torno a don Quijote, interpretado por los cineastas de modo diverso según los tiempos -siempre cambiantes- y el espíritu de la época, decisivo en la conformación de los cánones estéticos. Más concreta pero no de menor interés será la apuesta de Heidi Grünewald al centrarse en el análisis del Don Quichotte (1932) de Georg Wilhelm Pabst, primera película sonora del cineasta austriaco. Grünewald aborda la recpeción de la película en Alemania, interpretando la reformulación del mito a partir del ascenso del nacionalsocialismo, el exilio o el desarraigo.

Si el cine ha prodigado numerosos ejemplos del mito cervantino, será el auge de series de televisión como El ministerio del tiempo el motor que avive el despliegue de los modelos cervantinos en los medios audiovisuales. El estudio pionero de Carmen María López ("Puesto ya el pie en el estribo: Notas sobre los mundos posibles cervantinos en 'El ministerio del tiempo'") parte del enfoque de la narración serial para abordar el capítulo "Tiempo de Hidalgos" de la aclamada serie de televisión dirigida por Marc Vigil y creada por Pablo y Javier Olivares. En su aproximación a la dinámica narrativa de los mundos posibles cervantinos, estudia dos procedimientos entrelazados: la ciencia ficción y los viajes en el tiempo. Partiendo de una metodología comparativa, y con el fin de aproximarse a los guiños intertextuales de calado histórico, literario y cinematográfico, la autora examina distintos núcleos de sentido -el episodio de Grisóstomo en el marco de la literatura pastoril, la relación de Cervantes con el teatro a partir de la hipotética representación de Los baños de Argel, el viaje futurista a 2016, así como la posteridad y aclimatación del personaje como clásico-, moldeados en el formato de la narración serial. Cierra el bloque temático el estudio de Delio De Martino dedicaado al influjo de Cervantes en el marco de la publicidad ("Mitos y leyendas de Cervantes en la publicidad". Distintos tópicos de la obra cervantina, como el amor entre Don quijote y Dulcinea o la lucha contra los molinos de viento, devienen imágenes canónicas aprovechables en narraciones publicitarias para llevar la obra de Cervantes a la dinámica del marketing en una sociedad capitalista y global.

La quinta sección suscita gran interés al abordar el legado del mito cervantino en la filosofía y en la historia. Será Madga Polo Pujadas quien ofrezca una interpretación filosófica del Quijote a partir de la música de Strauss (“'Don Quixote' de Richard Strauss. Música y filosofía entre Apolo y Dioniso"). Profundiza para ello en el contexto de la Viena finisecular en que Strauss logró plasmar la decadencia de su tiempo a través del poema sinfónico Don Quijote op. 35. Variaciones fantásticas sobre un tema de carácter caballeresco para gran orquesta. De su estudio se desprende la tensión entre lo apolíneo y lo dionisíaco en la dialéctica del personaje, trasuntado ahora tema musical, a partir de elementos filosóficos como el eterno retorno nietzscheano, o el influjo del mundo como voluntad schopenhaueriana. El siguiente estudio de Daniel Migueláñez aborda el mito de la españolidad del Quijote en la filosofía española actual. Aborda para ello el concepto del héroe mitificado que es don Quijote, para preguntarse si la españolidad es un rasgo inherente al personaje o una condición accesoria, prescindible y, por ende, mitificada, carente de toda revelancia literaria y social. Para bascular las posiciones de 


\section{LA RECEPCIÓN DE CERVANTES EN LOS SIGLOS XX Y XXI: ITINERARIOS DEL MITO DEL QUIJOTE EN DISTINTAS ARTES - Editora: Paloma Ortiz de Urbina}

su ensayo se apoyará en las aportaciones que tres grandes filósofos y escritores del siglo XX (Unamuno, Ortega y Savater) han ofrecido en torno a este asunto. El estudio que sigue ("El honor, la nobleza y el Quijote en el siglo XX: Alfonso García Valdecasas y la recepción de los valores nobiliarios") de José Antonio Guillén se centra en el concepto de honor y nobleza en El hidalgo y el honor (1948) Alfonso García Valdecasas. Su estudio arroja luz sobre los valores sociales universales de honor, virtud y excelencia tradicionalmente atribuidos a lo nobiliario y, por extensión, al hidalgo cervantino.

Gran relieve ofrece en este marco el estudio de Inmaculada Donaire titulado "Psicología del Quijote y el quijotismo' de Santiago Ramón y Cajal: la respuesta de un intelectual ante la decadencia de España". En él analiza el discurso "La psicología de don Quijote de la Mancha y el quijotismo", con que el médico e intelectual Ramón y Cajal intervino en la sesión solemne que tuvo lugar en el Colegio de Médicos San Carlos el 9 de mayo de 1905, dentro de los actos conmemorativos del tercer centenario del Quijote. La tesis principal de Ramón y Cajal, según interpreta la autora, se sustenta en la superación de la decadencia moral, económica e institucional de España, en la medida en que el quijotismo es la antítesis del idealismo al que se aferran empresas materialmente imposibles. Este ideario cuajó en el enfoque médico experimental de la investigación científica de Ramón y Cajal, semilla del generacionismo y de la necesaria modernización de España que auspició en torno a 1905. Será el estudio de Miguel Salmerón Infante el que ponga el broche de cierre a este bloque, preguntándose por "Cervantes y el dolor por el mito ausente". A partir de la confrontación de dos mitos, el colectivo político de la Monarquía Universal y el vivencia de la Edad de Oro, ausculta las reflexiones de Américo Castro y Jean Canavaggio en torno al mito cervantino.

Ponderando el necesario marco intercultural en que se inscribe el hecho literario, el sexto bloque reflexiona sobre la influencia de Cervantes en otras lenguas y culturas. $\mathrm{Si}$ bien las traducciones del Quijote han alcanzado a casi todas las lenguas del mundo, la recepción de Cervantes en Oriente fue tardía. Esta cuestión ocupará el estudio de Valero-Garcés y Traicharoenwiwat "("El mito del Quijote en Oriente y su traducción al tailandés") para explorar las razones de ese retraso y recuperar el corpus de traducciones del Quijote realizadas en Japón, Corea o China. Las investigadoras darán a conocer los retos lingüísticos, pragmáticos y socioculturales que circundaron las labores traductológicas de la obra de Cervantes. El volumen integra el anexo "Cervantes y Argel", obra de Emilio Sola, prólogo a la última edición de El Quijote editada por el Instituto Cervantes de Argel y que, hasta la fecha, únicamente había sido publicada en lengua árabe.

En síntesis, la obra congrega un poliedro de ensayos en que prevalece el enfoque desde los estudios de recepción, orientando el análisis hacia las formas de interpretar en distintas disciplinas (filosofía, historia, música, literatura, medios audiovisuales) la figura de Don Quijote como mito literario. 